\title{
Penurunan Produk Cacat Dengan Metode Six Sigma Dan Continuous Improvement Di PT. Cakra Guna Cipta
}

\author{
Deni Kurniawan ${ }^{1}$ \\ Program Studi Teknik Industri, Fakultas Teknologi Industri Institut Teknologi Nasional Malang \\ *E-mail: denikurniawan424@ymail.com
}

\begin{abstract}
Abstrak
PT. Cakra Guna Cipta, Malang adalah perusahaan yang memproduksi rokok salah satunya rokok kretek (SKT). Banyaknya produk cacat menyebabkan perusahaan mengalami kerugian. Untuk itu, diperlukan suatu metode yang dapat menurunkan produk cacat rokok kretek yang nantinya dapat meningkatkan kualitas produksi sehingga perusahaan dapat memenangkan persaingan. Penelitian ini menggunakan metode Six Sigma dan Continuous Improvement. Six Sigma dimulai dengan tahapan DMAIC (Define, Measure, Analyze, Improve, Control). Tahap Define menetapkan karakteristik kualitas (CTQ), Measure perhitungan (Analisis Diagram Control P-Chart, DPMO dan Sigma Level). Tahap Analyze menggunakan diagram pareto dan diagram sebab akibat untuk mencari dan menentukan penyebab cacat rokok serta mencari solusi dari masalah tersebut. Tahap Improve menentukan langkah-langkah yang harus dilakukan untuk menurunkan cacat dalam proses produksi. Tahap Control dilakukan uji coba dari rencana perbaikan yang telah ditetapkan. Selanjutnya digunakan metode Continuous improvement melalui tahapan PDCA (Plan, Do, Check, Action). Tahap Plan merencanakan perbaikan pada proses produksi rokok kretek. Tahap Do memberikan solusi perbaikan agar proses produksi dapat berjalan lebih lancar. Tahap Check melakukan pengecekan agar dapat mengetahui sejauhmana rencana yang telah dibuat dapat direalisasikan. Tahap Action merespon seluruh hasil perencanaan, pelaksanaan, dan pengecekan yang bertujuan untuk mencegah timbulnya permasalahan yang sama. Berdasarkan perhitungan sebelum perbaikan diperoleh DPMO 9823,7 dan Sigma Level 3.84. Setelah dilakukan perbaikan diperoleh penurunan nilai DPMO menjadi 4403,2 dan Sigma Level sebesar 4.12 dan proporsi cacat tertinggi berkurang dari $4.19 \%$ menjadi $2 \%$. Berdasarkan tahapan PDCA, peneliti menyarankan perusahaan memberikan operator alat bantu Scrapper untuk meratakan tembakau di atas kain Mori sehingga diperoleh kepadatan rokok sesuai standar yang ditetapkan.
\end{abstract}

Kata Kunci : Produk Cacat, Six Sigma, Continuous Improvement, PDCA.

\section{Pendahuluan}

Perkembangan industri di Indonesia sangat pesat, apalagi dalam era globalisasi sekarang ini. Proses produksi sering terkendala oleh produk cacat. Berdasarkan hal tersebut, pengendalian kualitas memiliki peran penting dalam kegiatan produksi. Jika jumlah produk cacat terus meningkat, maka target produksi tidak dapat terpenuhi sehingga merugikan perusahaan secara finansial. Oleh karena alasan tersebut, maka perusahaan dituntut untuk menghasilkan produk yang benar-benar berkualitas, agar bisa menang dalam bersaing dengan perusahaan lain yang sejenis[1].

Salah satu masalah yang dihadapi oleh PT. Cakra Guna Cipta adalah banyaknya produk yang cacat sehingga perusahaan rugi, juga tingginya tingkat persaingan yang menyebabkan perusahaan berupaya meningkatkan kualitas produk Rokok agar bisa diterima dengan rasa puas oleh konsumen. Ketika banyak pelanggan tidak puas, berarti perusahaan tersebut siap-siap gulung tikar.

Penelitian ini bertujuan untuk mendapatkan penurunan produk cacat rokok kretek di PT. Cakra Guna Cipta dengan metode Six Sigma dan Continuous Improvement, sehingga menghasilkan produk yang benar-benar berkualitas tinggi guna meningkatkan penjualan produksi rorok (SKT). 


\section{Metode Penelitian}

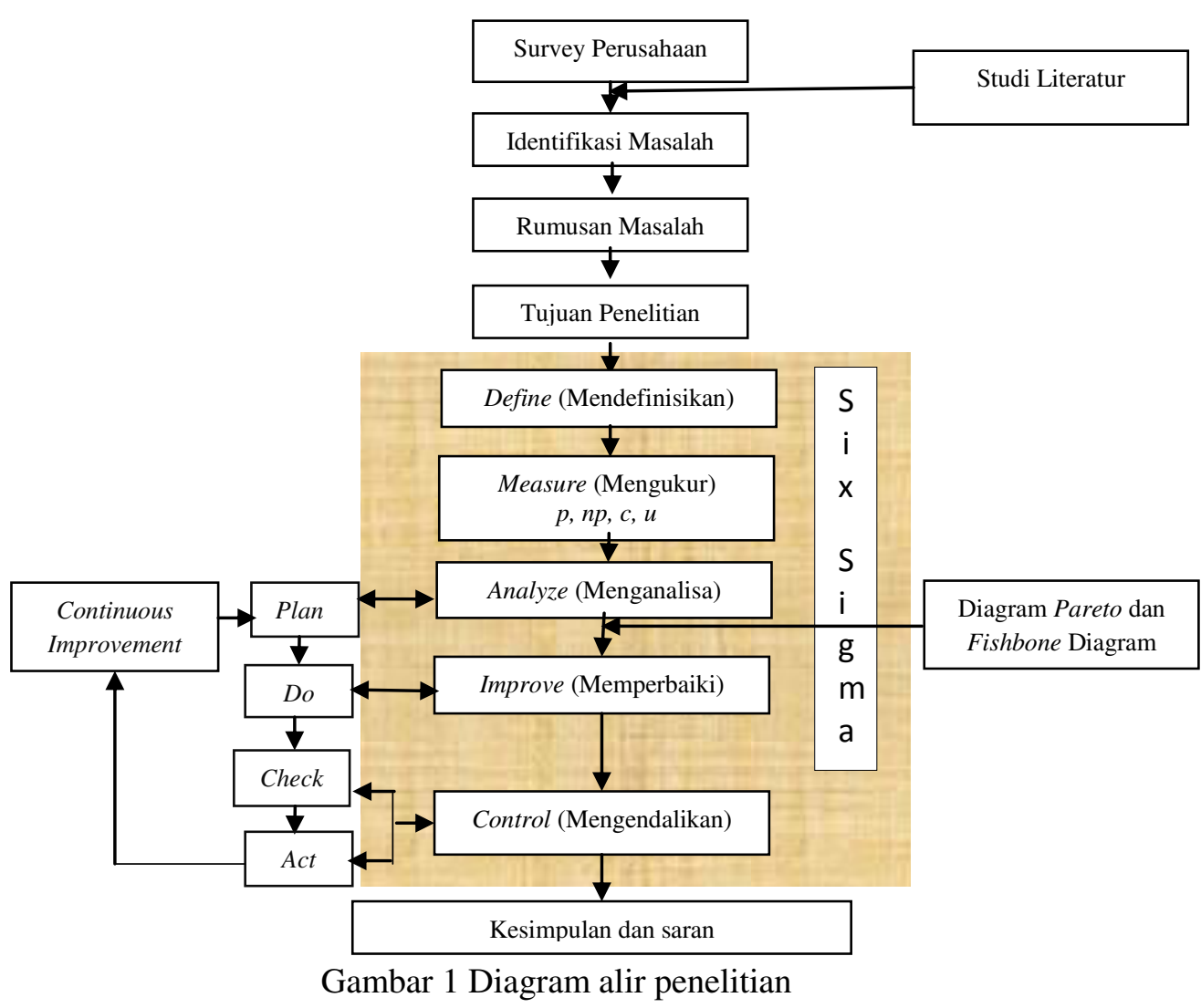

1. Survey perusahaan atau Studi pendahuluan

Survey yang dilakukan untuk melihat, mengetahui, mempelajari, dan memahami kondisi lingkugan perusahaan baik internal maupun ekternal PT. Cakra Guna Cipta.

2. Studi Literatur

Studiliteratur dilakukan dengan cara mempelajari teori dan ilmu pengetahuan yang berhubugan dengan permasalahan yang ada untuk mencari penyelesaian yang tepat.

3. Identifikasi Masalah

Identifikasi masalah dimulai dari mencari sebab timbulnya masalah lalu digunakan untuk mencari pemecahan yang tepat untuk keluar dari masalah tersebut dan memperbaiki kekurangan perusahaan.

4. Perumusan Masalah

Dilakukan untuk merumuskan masalah yang ada setelah studiliteratur yang berkaitan dengan masalah-masalah didalam perusahaan yang berhasil diidentifikasi.

5. Pengumpulan Data

Penyusunan pengumpulan data dan informasi yang meliputi beberapa macam data antara lain data produk rokok, data cacat produk dan data-data lain yang digunakan untuk penelitian ini.

6. Pengolahan Data dan Analisis Data

Setelah data dan informasi terkumpul langkah selanjutnya adalah menganalisa dan mengolah data yang diperlukan menentukan CTQ (penentuan Critical To Quality) dan DPMO.

7. Perhitugan kemampuan proses

Pada tahap ini data-data mengenai DPMO (defect per million opportunities) dan level sigma lalu selanjutnya dihitung kemampuan prosesnya (process capability) dengan tahapan DMAIC (define,measure, analyse, improve,control), SelanjutnyamelakukanperhitunganContinuous Improvement dengan tahapan PDCA (plan-do,check,art) 
8. Kesimpulan

Masukan dari hasil analisa dan pengolahan data serta perhitugan kemampuan proses (process capability) maka penyusun membuat kesimpulan untuk diberikan kepada pihak-pihak yang membutuhkan.

\section{Hasil dan Pembahasan}

\section{* Six Sigma (DMAIC)}

a. Define

Tahap Define merupakan tahap pertama dalam program peningkatan kualitas metode Six Sigma[2]. Berdasarkan pengamatan yang telah dilakukan di PT. Cakra Guna Cipta produksi rokok kretek manual (SKT) ada beberapa jenis cacat yang sering ditemui, diantaranya adalah sebagai berikut: Rokok terlalu keras, kertas/ambri bernoda, kertas rokok miring, pemotongan ujung rokok tidak rata.

\section{b. Measure}

Tahap Measure merupakan langkah yang kedua dalam analisis Six Sigma. Pada tahap ini dilakukan perhitungan Analisis Diagram Control P-Chart, nilai DPMO dan Sigma level, pada Tabel 1, Tabel 2[3].

\section{- Analisis Diagram Control (P-Chart)}

Berdasarkan Tabel 1, diperoleh nilai sigma proporsi cacat tertinggi yaitu 0,049718695 sedangkan nilai proporsi cacat terendah yaitu 0,026103042 .

Tabel 1 Data Proporsi Cacat

\begin{tabular}{|l|l|l|}
\hline Data Produksi (batang) & Cacat (batang) & Proporsi Cacat (\%) \\
\hline 799.121 & 26.869 & 0,033623193 \\
\hline 838.988 & 32.837 & 0,03913882 \\
\hline 846.999 & 36.178 & 0,043350701 \\
\hline 833.121 & 26.463 & 0,031763693 \\
\hline 845.457 & 22.069 & $\mathbf{0 , 0 2 6 1 0 3 0 4 2}$ (Terendah) \\
\hline 796.111 & 39.569 & 0,049702868 \\
\hline 771.988 & 33.808 & 0,043793427 \\
\hline 751.202 & 28.814 & 0,038357193 \\
\hline 771.021 & 37.698 & 0,04889361 \\
\hline 800.021 & 39.776 & $\mathbf{0 , 0 4 9 7 1 8 6 9 5}$ (Tertinggi) \\
\hline 847.072 & 30.178 & 0,035626251 \\
\hline 885.937 & 27.877 & 0,03146612 \\
\hline
\end{tabular}

\section{- DPMO dan Sigma Level}

Berdasarkan Tabel 2 Diketahui bahwa DPMO 9.823,7 dan nilai Sigma 3.84 (rata-rata kinerja industri di Indonesia)

Tabel 2 Data nilai DPMO dan nilai Sigma Level

\begin{tabular}{|c|c|c|c|c|}
\hline Bulan & $\begin{array}{c}\text { Jumlah Produksi } \\
\text { (Batang) }\end{array}$ & $\begin{array}{c}\text { Jumlah cacat } \\
\text { (Batang) }\end{array}$ & DPMO & Nilai Sigma \\
\hline Januari & 799.121 & 26.869 & $8.405,798$ & 3,89 \\
\hline Februari & 838.988 & 32.837 & $9.784,705$ & 3,88 \\
\hline Maret & 846.999 & 36.718 & $10.837,68$ & 3,76 \\
\hline April & 833.121 & 26.463 & $7.940,923$ & 3,91 \\
\hline Mei & 845.457 & 22.069 & $6.525,761$ & 3,98 \\
\hline Juni & 796.111 & 39.569 & $12.425,72$ & 3,74 \\
\hline Juli & 771.988 & 33.808 & $10.948,36$ & 3,79 \\
\hline Agustus & 751.202 & 28.814 & $9.589,298$ & 3,75 \\
\hline September & 771.021 & 37.698 & $12.223,4$ & 3,74 \\
\hline Oktober & 800.021 & 39.776 & $12.429,67$ & 3,87 \\
\hline November & 847.072 & 30.178 & $8.906,563$ & 3,92 \\
\hline Desember & 885.937 & 27.877 & $7.866,53$ & 46,07 \\
\hline Jumlah & 9.787 .038 & 382.136 & $117.884,4$ & 3,839167 \\
\hline Rata-rata & 815.587 & 31.845 & $9.823,7$ & \\
\hline
\end{tabular}




\section{c. Analyze}

Tahap Analyze dilakukan dengan menggunakan Six Sigma Tools yaitu: Diagram Pareto, dan Diagram Sebab Akibat[4].

\section{Analisis Diagram Pareto}

Tabel 3 Data Jumlah cacat (Defect)

\begin{tabular}{|c|c|c|c|}
\hline No & Kategori cacat & $\begin{array}{c}\text { Jumlah } \\
\text { (batang) }\end{array}$ & $\begin{array}{c}\text { Persentase Defect } \\
(\%)\end{array}$ \\
\hline 1 & Rokok terlalu keras & 273.282 & 71.41 \\
\hline 2 & Kertas/ambri miring & 52.127 & 13,62 \\
\hline 3 & Kertas/ambri bernoda & 34.197 & 8,94 \\
\hline 4 & Pengguntingan kurang rata & 23.070 & 6.03 \\
\hline \multicolumn{2}{|l}{ Jumlah } & 382.676 & 100 \\
\hline
\end{tabular}

Berikut adalah diagram pareto dari data yang telah didapatkan:

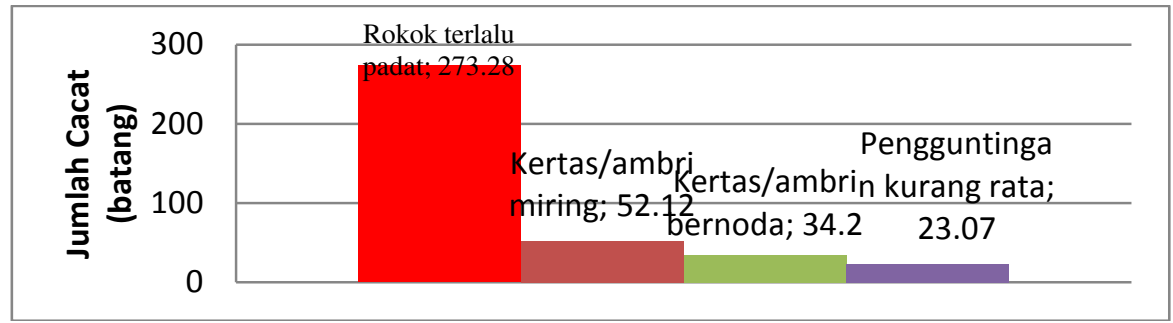

Gambar 2 Diagram Pareto

Berdasarkan Tabel 3 dan Gambar 2 maka dapat diketahui bahwa rokok terlalu keras mempunyai nilai kontribusi terbesar pada jumlah produk cacat yaitu 273.28 atau kurang lebih $71.41 \%$ dari total keseluruhan produk cacat yang didapat.

\section{- Analisis Diagram Sebab Akibat}

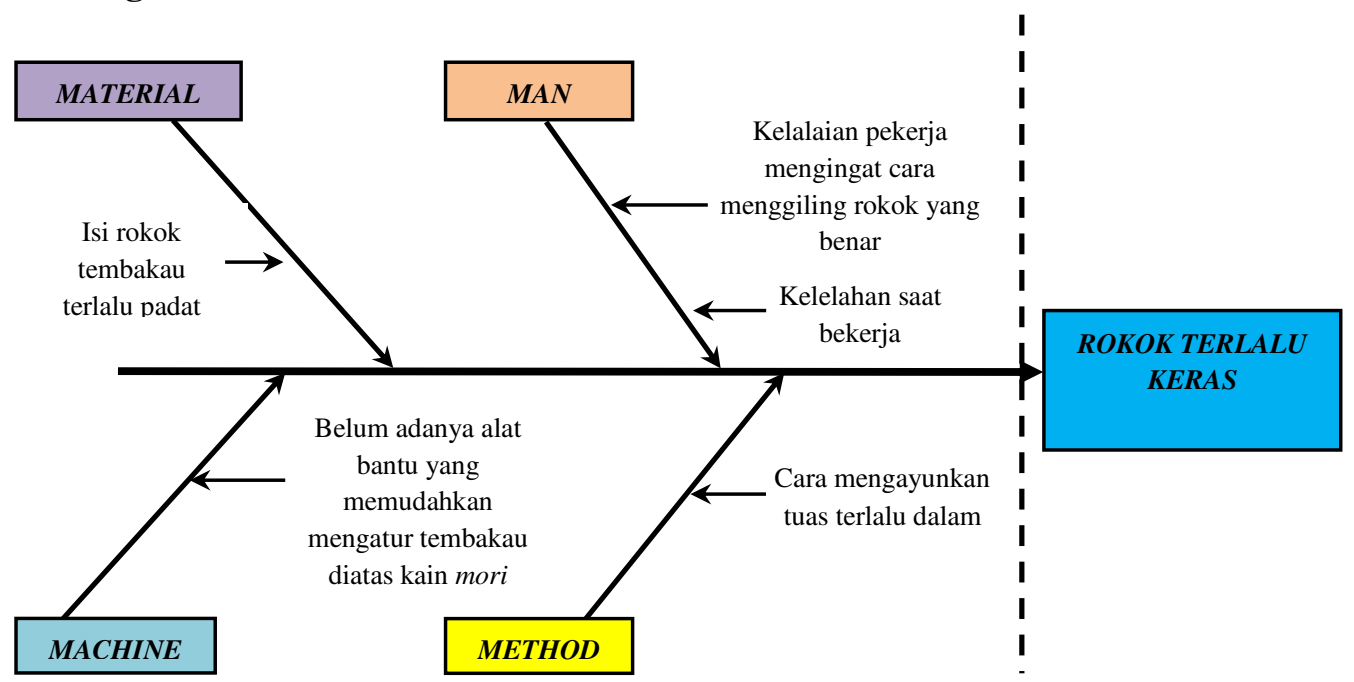

Gambar 3 Diagram Sebab Akibat

Dari Gambar 3 terlihat Isi rokok terlalu keras karena tembakau terlalu padat dan cara mengayunkan tuas dari alat giling terlalu dalam. Cara pengisian yang kurang tepat dikarenakan belum ada alat bantu yang memudahkan mengatur tembakau diatas kain Mori.

\section{d. Improve}

memperbaiki proses untuk menghilang cacat. Setelah sumber-sumber dan akar penyebab dari masalah kualitas terindetifikasi, maka perlu dilakukan penetapan rencana tindakan (action plan) untuk melaksanakan peningkatan kualitas Six Sigma[5]. 
Tabel 4 Perbaikan

\begin{tabular}{|l|l|}
\hline Penyebab & Penanganan \\
\hline $\begin{array}{l}\text { Belum adanya alat bantu yang memudahkan } \\
\text { mengatur tembakau diatas kain mori. }\end{array}$ & $\begin{array}{l}\text { Menambahkan alat bantu untuk mengatur } \\
\text { tembakau diatas kain mori. }\end{array}$ \\
\hline Cara mengayunkan tuas terlalu dalam. & $\begin{array}{l}\text { Perlu menambahkan waktu pelatihan kepada } \\
\text { operator agar lebih baik saat menggiling } \\
\text { rokok kretek supaya hasil lebih optimal. }\end{array}$ \\
\hline $\begin{array}{l}\text { Bahan baku terlalu banyak diatas kain mori } \\
\text { sehingga produk rokok yang dihasilkan } \\
\text { terlalu keras. }\end{array}$ & $\begin{array}{l}\text { Selalu memperhatikan tembakau diatas kain } \\
\text { mori agar rokok kretek yang dihasilkan } \\
\text { sesuai dengan kualitas yang telah ditetapkan. }\end{array}$ \\
\hline Kelelahan disaat bekerja & $\begin{array}{l}\text { Memperbaiki proses produksi dengan cara } \\
\text { mengurangi produk cacat. }\end{array}$ \\
\hline
\end{tabular}

Berdasarkan Tabel 4, proses produksi ini sering mengalami kendala, yaitu tidak ada alat untuk memudahkan mengatur tembakau di atas kain mori yang sangat beresiko pada hasil akhir produksi rokok kretek (SKT) dan kurangnya ketelitian dan kurangnya keahlian dalam pengilingan rokok yang mengakibatkan rokok terlalu keras.

\section{e. Control}

Tahap Control merupakan tahap operasional terakhir dari siklus DMAIC, di mana pada tahap ini akan dibuat mekanisme kontrol dan mendokumentasikan proyek[6]. Hasil-hasil peningkatan kualitas didokumentasikan dan disebarluaskan kepada para karyawan.

- Data Produksi Setelah Perbaikan

Berdasarkan Tabel 5, diperoleh nilai sigma proporsi cacat tertinggi yaitu 0.02002773 sedangkan nilai proporsi cacat terendah yaitu 0.016036036 .

Tabel 5 Data ekspetasi Proporsi Cacat setelah perbaikan

\begin{tabular}{|c|c|c|}
\hline Data Produksi (batang) & Cacat (batang) & Proporsi Cacat (\%) \\
\hline 28.846 & 577 & $\mathbf{0 , 0 2 0 0 0 2 7 7 3}$ \\
\hline 27.407 & 493 & 0,017988105 \\
\hline 27.676 & 471 & 0,017018355 \\
\hline 28.280 & 524 & 0,018528996 \\
\hline 27.750 & 445 & $\mathbf{0 , 0 1 6 0 3 6 0 3 6}$ \\
\hline 27.965 & 462 & 0,016520651 \\
\hline 27.741 & 477 & 0,017194766 \\
\hline
\end{tabular}

\section{- $\quad$ DPMO dan Nilai Sigma}

Berdasarkan Tabel 6, dapat diketahui bahwa DPMO 4403,203 dan nilai Sigma 4.12 (rata-rata kinerja industri di Amerika Serikat)

Tabel 6 Data $D P M O$ dan nilai Sigma level Setelah Perbaikan

\begin{tabular}{|c|c|c|c|c|}
\hline Hari/tanggal & $\begin{array}{c}\text { Jumlah } \\
\text { produksi }\end{array}$ & $\begin{array}{c}\text { Jumlah } \\
\text { cacat }\end{array}$ & DPMO & $\begin{array}{c}\text { Nilai } \\
\text { Sigma }\end{array}$ \\
\hline 2-juni-2016 & 28.846 & 577 & 5000,693 & 4,07 \\
\hline 3-juni-2016 & 27.407 & 493 & 4497,026 & 4,12 \\
\hline 6-juni-2016 & 27.676 & 471 & 4254,589 & 4,13 \\
\hline 7-juni-2016 & 28.280 & 524 & 4632,249 & 4,10 \\
\hline 8-juni-2016 & 27.750 & 445 & 4009,009 & 4,15 \\
\hline 9-juni-2016 & 27.965 & 462 & 4130,163 & 4,14 \\
\hline 10-juni-2016 & 27.741 & 477 & 4298,691 & 4,13 \\
\hline Jumlah & 195.665 & 3449 & 30822,42 & 28,84 \\
\hline Rata-rata & 27.952 & 492,7143 & 4403,203 & 4,12 \\
\hline
\end{tabular}

\section{* Continuous Improvement PDCA (Plan-Do-Check-Action)}

\section{Plan}

Tahap Plan adalah melakukan analisa kondisi yang ada[7]. Berdasarkan diagram Sebab akibat gambar 3, dapat dibuat perencanaan perbaikan pada proses produksi rokok kretek. Peneliti menyarankan agar perusahan memberikan operator alat bantu. 
Do

Tahap Do Rencana yang telah diimplementasikan secara bertahap, mulai dari skala kecil selama periode waktu tertentu[8]. Tindakan penaggulangan atau solusi perbaikan dapat digambarkan sebagai berikut:

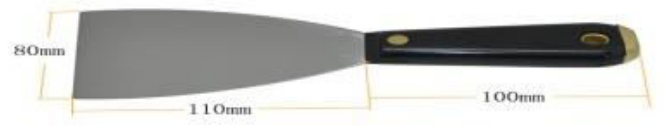

Spesifikasi:

Gambar 4 Scrapper

Material : Stainless Steel

Handle : Plastic Handle

\section{Check}

Tahap Check memeriksa atau meneliti merujuk pada penetapan apakah pelaksananya berada dalam jalur, sesuai dengan rencana dan memantau kemajuan perbaikan yang direncanakan[9].

- Sebelum perbaikan

1. Nilai DPMO dan nilai Sigma level: DPMO 9.823,7 dan nilai Sigma 3.84.

2. Berdasarkan hasil dari Tabel 1 dapat dilihat Nilai proporsi cacat tertinggi yaitu (4.9\%) sedangkan nilai proporsi cacat terendah yaitu $(2.6 \%)$.

- Setelah perbaikan

1. Nilai DPMO dan nilai Sigma level: DPMO 4403,203 dan nilai Sigma level 4.12.

2. Berdasarkan hasil dari table 5 dapat dilihat Nilai proporsi cacat tertinggi yaitu (2\%) sedangkan nilai proporsi cacat terendah yaitu $(1.6 \%)$.

Maka dapat disimpulkan bahwa, setelah perbaikan proposi cacat menurun dari $4.9 \%$ menjadi $2 \%$. Sementara itu, nilai Sigma Level meningkat dari 3.84 menjadi 4.12.

\section{Action}

Tahap Action penyesuaian berkaitan dengan standarisasi prosedur baru guna menghindari timbulnya kembali masalah yang sama atau menetapkan sasaran baru untuk perbaikan berikutnya[10].

\section{Kesimpulan}

a. Konsep DMAIC (Define, Measure, Analyze, Improve, Control) pada PT. Cakra Guna Cipta dapat mengurangi cacat rokok kretek (SKT). Hal ini dapat diketahui dari peningkatan nilai $D P M O$ dari rata-rata kinerja industri di Indonesia ke rata-rata kinerja industri di Amerika Serikat dan meningkatnya nilai Sigma Level setelah dilakukan perbaikan.

b. Berdasarkan factor penyebab cacat rokok terlalu keras yang dilakukan melalui pengamatan dan wawancara, maka diperoleh prioritas utama perbaikan pada factor manusia yaitu kecerobohan (kurang teliti) dan tidak adanya alat bantu untuk mertakan tebakau diatas kain Mori.

c. Metode PDCA (plan-do-check-action) dapat menjadi salah satu metode yang sistematis untuk memfasilitasi PT. Cakra Guna Cipta dalam melakukan aktivitas perbaikan, terutama dalam permasalahan kualitas produksi.

Berdasarkan pengumpulan data dan pengolahan data dengan menggunakan metode Six Sigma dan Continuous Improvement, maka dapat diambil kesimpulan bahwa: dengan ini membuktikan perbaikan mampu menurunkan produk cacat secara signifikan. 


\section{Daftar Referensi}

[1] Nurul Shabrina, dkk. Peningkatan Kualitas Produk Kerudung Instan Menggunakan Metode Six Sigma, Jurnal Teknik Industri, Institut Teknologi Nasional Bandung, Vol. 02, No. 03, 2014.

[2] Tantri Windarti. Pengendalian Kualitas Untuk Meminimasi Produk Cacat Pada Proses Produksi Besi Beton, Jurnal Teknik Industri Universitas Diponegoro, Vol. IX, No. 03, September 2014.

[3] Gaspersz,Vincent. Pedoman Implmentasi Program Sig Sigma Terintegrasi Dengan ISO 9001:2000,MBNQA, Dan HACCP, PT. Gramedia Pustaka Jakarta, 2002.

[4] Hutabarat, J, Nursanti, E . Meningkatkan Kualitas Produk Melalui Konsep DMAIC Pada Six Sigma, Prosiding Seminar Nasional Teknologi V, Program Studi MMT-ITS, Surabaya, 2007.

[5] Gaspersz,Vincent. Total Quality Manajement, PT. Gramedia Pustaka Utama Jakarta, 2002.

[6] BoyIsmaPuta. Penerapan Metode Six Sigma Untuk Menurunkan Kecacatan Produk Frypan Di CV. Corning Sidoarjo, Jurnal Teknik Industri, Universitas Muhammadiyah Sidoarjo, Vol.11, No.2, halaman. 134-142, 2010.

[7] Jong Feliando Yonatan, Herry Christian Palit. Upaya Peningkatan Kualitas Dengan Metode PDCA Di PT. ASKI, Jurnal Titra, Vol. 3, No. 2, pp. 283-288, 2015.

[8] Tjiptono, Fandy, Diana Anastasia. Total Quality Manajement, PT. Andipratita Trikarsa Mulia, Yogyakarta, 1995.

[9] Sundana, S, Hartono. Penerapan Konsep Kaizen Dalam Upaya Menurunkan Cacat Apperance Unit Xenia-Avanza Proses Painting Di PT. Astra Daihatsu Motor, Seminar Nasional Sains Dan Teknologi, Universitas Muhammadiyah Jakarta, 12 November 2014.

[10] Darsono. Analisis Pengendalian Kualitas Produksi Dalam Upaya Mengendalikan Tingkat Kerusakan Produk, Jurnal EkonomiManajemen Akutansi, No. / Th. XX/ Oktober 2013. 